\title{
CITES: In Sickness and in Health?
}

Mass mortality events in wildlife associated with disease and multiple stressors appear to be increasing (Fey and others 2015), and a lack of rapid access to diagnostic analyses can hamper conservation responses. Timely diagnosis is a crucial factor for effective disease investigation and response in humans and agricultural species, but it is also critical for wildlife conservation in the face of mass mortality. Rapid and accurate diagnoses, especially for unusual agents or in unusual species, often require advanced laboratory techniques which are currently unavailable in many countries. Efficient international collaboration among field and laboratory staff can therefore be critical for effective conservation.

The Convention on International Trade in Endangered Species of Wild Fauna and Flora (CITES) regulates movement of species threatened with extinction. Under CITES, diagnostic specimens from listed species are effectively considered trade products, requiring permits for international movement. While due process is surely warranted to prevent overexploitation and ensure fair and equitable use of genetic material, mechanisms are critically needed for rapid international transfer of diagnostic specimens in emergency situations.

For example, the current permitting system hindered timely investigation of a 2015 mass die-off of Saiga antelope in Kazakhstan that depleted $>50 \%$ of the global population (Orynbayev and others 2016). Acquiring CITES export and import permits took 5 months. An import permit can only be issued once an export permit is available, with complicated paperwork and procedures.

Determining toxicological, infectious or other causes (e.g. starvation, weather) of physiological stress may require testing at numerous laboratories with iterative diagnostic pathways. Each submission requires separate paperwork and costs, a disincentive to international collaboration among often under-resourced wildlife authorities. Untimely move- ment and processing may also present technical challenges. In any given setting, a gap in cold chain may compromise sample quality if proper storage facilities are not available in addition to delaying access to critical information that could inform control measures.

Solutions to facilitate international collaboration to control disease impacts on threatened and endangered species are critically needed. A recent CITES-OIE collaborative agreement (CITES-OIE 2015) may provide a framework for a new pathway for collaboration. Through a mechanism that could be agreed upon by CITES, international or regional reference laboratories officially linked to the World Organisation for Animal Health (OIE) may offer assurance for protecting data rights and confidentiality concerns, provide financial resources for thorough analyses not readily available in conservation, and fit within existing international agreements related to cross-border "trade". We strongly support these efforts and urge EcoHealth readers and interested parties to raise awareness of this issue at this September's meeting of the CITES Conference of the Parties, at which member countries could enact a strategy to resolve the existing bottleneck. This first step will reinforce the commitment of CITES signatories to the plight of threatened and endangered species in sickness and in health.

William B. Karesh, ${ }^{1,2,3}$ Richard Kock, ${ }^{1,4}$ and Catherine C. Machalaba ${ }^{1,2}$

${ }^{1}$ IUCN SSC Wildlife Health Specialist Group, Rue Mauverney 28, 1196 Gland, Switzerland

${ }^{2}$ EcoHealth Alliance, 460 West 34th St, 1701, New York, NY, USA

${ }^{3}$ World Organisation for Animal Health (OIE), 12 rue du Prony, Paris 75017, France 
${ }^{4}$ The Royal Veterinary College, Hawkshead Lane, North Mymms, Hatfield, Hertfordshire AL9 7TA, UK

e-mail: karesh@ecohealthalliance.org

\section{REFERENCES}

CITES-OIE (2015). Cooperation Agreement between The Secretariat of the Convention on International Trade in Endangered Species of Wild Fauna and Flora (CITES Secretariat) and The World Organisation for Animal Health (OIE).
Fey SB, Siepielski AM, Nussle S, Cervantes-Yoshida K, Hwan JL, Huber ER, et al. (2015) Recent shifts in the occurrence, cause, and magnitude of animal mass mortality events. Proceedings of the National Academy of Sciences of the United States of America 112:1083-1088

Orynbayev MB, Beauvais W, Sansyzbay AR, Rystaeva RA, Sultankulova KT, Kerimbaev AA, et al. (2016) Seroprevalence of infectious diseases in saiga antelope (Saiga tatarica tatarica) in Kazakhstan 2012-2014. Preventive Veterinary Medicine 127:100104

Published online: August 19, 2016 